\section{Telerehabilitation (Remote Therapy)}

\author{
Kenneth N. K. Fong ${ }^{1}$ and Rick Kwan ${ }^{2}$ \\ ${ }^{1}$ Department of Rehabilitation Sciences, \\ The Hong Kong Polytechnic University, \\ Hung Hom, HongKong SAR \\ ${ }^{2}$ Centre for Gerontological Nursing, \\ School of Nursing, The Hong Kong Polytechnic \\ University, Hung Hom, HongKong SAR
}

\section{Synonyms}

Tele-rehab

\section{Definition}

Telerehabilitation (TR) is the use of information and communication technology to provide rehabilitation services at a distance (Brennan et al. 2011; Kairy et al. 2009; McCue et al. 2010). Telerehabilitation can be considered a subfield or a branch of telemedicine consisting of a remote technology system to control rehabilitation at a distance (Peretti et al. 2017). Telemedicine is the delivery of healthcare services by healthcare professionals, where distance is a critical factor, using information and communication technologies to exchange valid information for the diagnosis, treatment, and prevention of diseases and injuries, for research and evaluation, and for the continuing education of healthcare providers, all in the interest of advancing the health of individuals and their communities (World Health Organization, Group Consultation on Health Telematics 1998). The World Federation of Occupational Therapists (2014) has preferred to use the term telehealth to describe the service delivery model of TR, teletherapy, or telecare, which is the use of information and communication technologies to deliver health-related services when the provider and client are in different physical locations (World Federation of Occupational Therapists 2014). The World Confederation for Physical Therapy (WCPT) and the International Network of Physical Therapy Regulatory Authorities (INPTRA) define digital practice as health care services, support, and information provided remotely via digital communication and devices for the purpose of digital physical therapy practice (WCPT and INPTRA 2019).

\section{Overview}

The crucial elements of "tele" in telerehabilitation are that the delivery and provision of health care and consultative services to individual patients involve: (1) the transmission of information related to care, (2) the transmission of that information over distance, and (3) the use of telecommunication technologies. In the field of rehabilitation, the intensity, frequency, and continuity of treatment, as well as early intervention 
as soon as possible, particularly after acute management of a disease during hospitalization, are very important. Telerehabilitation substitutes for conventional person-to-person interactions when rehabilitation infrastructures are difficult to reach due to the geographic location of patients, and it also allows patients to avoid using travel time to access their services (Peretti et al. 2017). In the past, TR was used mainly to bridge geographic separation and address the problem of spatial connection between service providers and patients, such as rural families (Cason 2009). It is becoming increasingly evident, however, that TR can help resolve some long-standing problems improving access to rehabilitation services, preventing unnecessary delays in the receipt of care (Cason 2014), and reducing the impact of shortages of rehabilitation professionals in underserved areas (Cason 2012).

Nowadays, TR is being used to monitor treatment outcomes in the community and outside purely clinical settings. Importantly, recent reviews have found that TR is cost-effective and has been shown to have clinical outcomes that are similar to those from person-to-person rehabilitation services, in various pathologies and impairments (Kairy et al. 2009). Telerehabilitation can also allow improved control of the content and format of self-management information and resources to the service providers (i.e., to maintain consistency) and can increase providers' ability to monitor standards of care and service user outcomes (WCPT and INPTRA 2019).

\section{Key Research Findings}

\section{Clinical Perspective}

The service delivery of TR involves four types of delivery: (1) teletherapy, which refers to direct patient training, therapeutic services, and treatment; (2) teleconsultation and follow-up services; (3) tele-education, which focuses on preventive patient education; and (4) telemonitoring, which refers to remote monitoring of patients. Telerehabilitation has been used extensively in different rehabilitation disciplines, with diverse applications of TR in different areas.
In physiotherapy, the Joint Digital Physical Therapy Task Force of the World Confederation of Physical Therapy (WCPT) and the International Network of Physical Therapy Regulatory Authorities (INPTRA) were established in 2017 and produced a resource paper, published in April 2019, on digital practice for physiotherapists (WCPT and INPTRA 2019). In addition, a literature review has analyzed 898 studies on the validity and reliability of Internet-based physiotherapy assessment for musculoskeletal disorders (Mani et al. 2016).

In speech therapy, by facilitating generalization of treatment effects within a person's everyday environment, TR has the capacity to optimize functional outcomes in communication and swallowing behaviors, and it enables monitoring to be carried out on a long-term basis. Several image-based TR applications have been used in the management of adult neurogenic speech and language disorders, stuttering, voice disorders, speech and language disorders in children, and laryngectomy care and swallowing dysfunction (Theodoros 2008).

In occupational therapy, the World Federation of Occupational Therapists (WFOT) has already acknowledged that TR is an appropriate service delivery model for occupational therapy services (WFOT 2014). A systematic review showed that occupational therapy via TR offered user-friendly at-home treatment for patients and found that both patients and caregivers were generally satisfied with the use of TR in providing occupational therapy services (Hung and Fong 2019).

In nursing, the National Telenursing Center was established to provide TR services in underserved populations that do not have easy access to healthcare services (Cross et al. 2018). A systematic review showed that nursing via TR employed various teletechnological tools, including telephones, websites, videoconferencing systems, and mobile devices, to deliver an array of health services for people with various health conditions, including chronic illnesses (e.g., heart failure, hypertension, diabetes, ulcerative colitis, stroke cancer), obstetrical and gynecological conditions (e.g., pregnancy, fibromyalgia), and education (Souza-Junior et al. 2016). 
Telerehabilitation has been applied with different age populations, including children and adolescents (Santos et al. 2014) and older adults (Botsis et al. 2008). Home telecare was first developed for patients with chronic diseases who preferred to live in their own homes for long-term care. Telerehabilitation can improve the independence of such patients in their activities of daily living and can enhance the quality of life in their living situation. Examples of applicable diagnostic groups include patients with neurologic disease (Block et al. 2016), coronary artery disease (Huang et al. 2015), and spinal cord injury (Dorstyn et al. 2013). Neurologic disease patients include those with stroke (Johansson and Wild 2011) and multiple sclerosis (Amatya et al. 2015), and two systematic reviews have already been published on the latter patient group by the same research team (Amatya et al. 2015; Khan et al. 2015). Intensive home-based monitoring has reduced hospital admissions and inpatient time for patients suffering from severe congestive heart failure (Kornowski et al. 1995). After the application of TR, moderate to strong evidence has been found for motor recovery in lower extremities during postoperative recovery (Agostini et al. 2015; Eysenbach et al. 2017) and also for patients after orthopedic surgery (Eysenbach et al. 2017).

There are many varieties of TR applications, ranging from physical exercise, skills training, use of assistive technology in home training, and environment modification, to education on the health promotion. TR has the benefit of creating a customized physical exercise program for patients in physical rehabilitation (Peretti et al. 2017). Skills training using TR has included visual-motor training (Criss 2013), hand-function training (Ferre et al. 2017), cognitive training (Bergquist et al. 2008) and cognitive orientation (Ng et al. 2013), sensory diet work (Gibbs and Toth-Cohen 2011), and energy conservation (Boehm et al. 2015). The incorporation of combined assistive technology with home training in TR applications has involved a web-based video game (Golomb et al. 2010; Reifenberg et al. 2017), smartphone applications (apps) (Lawson et al. 2017), functional electrical stimulation (Hermann et al. 2010), and robot-assisted devices
(Linder et al. 2015). Environment modification via TR has included home modification (Nix and Comans 2017). Education on the promotion of well-being has included home safety education (Breeden 2016) and a disability prevention program (Hegel et al. 2011).

In a recent systematic review of TR (Hung and Fong 2019), the frequency, duration, and length of intervention varied among different studies. The frequency ranged from intervention on a weekly basis (eight studies), to twice a week (two studies), to five times a week (three studies), and in one study it was performed on a daily basis. Regarding the duration of each session, treatment regimens ranged from $30 \mathrm{~min}$ per session (five studies), to $1 \mathrm{~h}$ (three studies), to $2 \mathrm{~h}$ (one study), to even $3 \mathrm{~h}$ per session (one study). In Hung and Fong's (2019) findings, the length of intervention ranged from 3 weeks to 3 months, but it seldom involved a follow-up session after intervention. Only three studies followed up with their participants: After 6 months, at 6 weeks, and 3 months after active intervention was completed.

\section{Technology Perspective}

Telerehabilitation began in the late 1990s with the development of Internet communication. With the evolving technology in the digital and mobile device realms, telecommunication services have been transformed since the introduction of smartphones to the commercial market in the mid to late 2000s. The TR technologies have been used before, in the form of Internetbased tools, web-based videoconferencing, smartphones, video phone-calling apps, and the like (Hung and Fong 2019). A range of hardware and software can be used for videoconferencing, training, monitoring, and assessment and/or recording; many older adults are getting familiar with such advanced technologies in time.

Nowadays, TR's emphasis is not only on the use of the Internet and smartphones, but also on other forms of mobile technology, through which it is now possible, for instance, to adopt wearable sensing technology and apply it in clinical practice for certain common disorders related to motor rehabilitation, mental health, general health, and physiological well-being. 
The mode of TR delivery can either be synchronous or asynchronous transmission of data - that is, it can be real-time interactions or store-andforward photos, videos, and messages between the service provider and the client (Hung and Fong 2019; WFOT 2014). Regarding the setup, Botsis et al. (2008) recommended that all home telecare systems for older people should fulfill the following requirements: (1) they must be simple to use and user-friendly; (2) they must be stable, interoperable without interruption, and reliable in their monitored values; (3) they must ensure computer security and data confidentiality; and (4) they have continuously available service.

Some TR applications require in-person sessions that are conducted either in clinics or in participants' homes, for prior equipment setup and training in the use of telemedia equipment (Bergquist et al. 2008; Breeden 2016; Ferre et al. 2017; Gibbs and Toth-Cohen 2011; Golomb et al. 2010; Hermann et al. 2010; Lawson et al. 2017; Linder et al. 2015). Currently, health apps that can be installed onto mobile devices such as smartphones and tablets have already been developed to promote behavioral change and health in the areas of alcohol abuse, asthma, breastfeeding, cancer, depression, diabetes, general health and fitness, headaches, heart disease, HIV, hypertension, iron deficiency/anemia, low vision, mindfulness, obesity, pain, physical activity, smoking, weight management, and women's health (McKay et al. 2018). Hand-held electronic, wristwatch-like and noninvasive devices that provide real-time recording and that allow transmission of data through the Internet or by email have been developed specifically for older people: portable electrocardiogram (ECG) signals for people after cardiac surgery, noninvasive blood glucose meters for people with diabetes, portable peakflow meters through smartphones for patients with asthma and chronic obstructive pulmonary disease, accelerometer sensors for fall prevention, motion-inertia sensors for detecting activity, and in general, intelligent pillboxes, weight and blood pressure monitors, and the like (Botsis et al. 2008). In the future, such features as care robots and sensors embedded in clothing that can be connected to the Internet, as well as artificial intelligence (AI)-assisted detection technology, will be used to monitor older patients' activities of daily living and their health conditions, as well as their physical activities and mental well-being, in their own home. With so much evolving technology, TR practitioners need to be aware of the evidence base that is associated with TR, and they must also acknowledge the lack of strong evidence in some areas, including emerging innovations (WCPT and INPTRA 2019). In all cases, therapists should apply sound clinical reasoning and follow standards of practice and codes of conduct (Botsis et al. 2008).

\section{Future Directions of Research}

Telerehabilitation faces certain challenges. For some types of diseases, such as musculoskeletal injuries and stroke, teletherapy cannot take the place of physical contact, especially in the form of manual therapy. Furthermore, several regulatory issues, including the scope and standards of TR practice, such as issues arising in the form of complaints, payment and reimbursement schedules for TR, a code of ethics of rehabilitation therapists, patients' consent for privacy and confidentiality, patients' safety, crisis management, and others, still require further exploration (WCPT and INPTRA 2019).

With the advance of teletechnology, however, health care services and training can more easily reach various populations. Healthcare services are also getting more complex. Complex interventions that combine different strategies (e.g., therapy, consultation and follow-up services, education, and health monitoring, which refers to remote monitoring of patients) will be delivered through various teletechnological platforms. Therefore, TR will continue to evolve as part of the larger concept of telehealth, in order to provide a wide range of healthcare services to solve a suite of complex healthcare problems in the future. Teletechnology, particularly in the forms of wearable devices (Hung et al. 2004), telerobotic systems (Sharifi et al. 2018), and augmented reality (Ponce et al. 2014), will develop significantly to enhance the efficiency of telehealth services. 
Telerehabilitation will even emerge as a blueprint for rehabilitation monitoring of patients during infectious disease pandemics, for example, the coronavirus (Covid-19) pandemic in 2020, especially where social distancing is restrictive. The effects of TR on clinical outcomes and patients' feedbacks on the utility of TR should be further evaluated in the future.

\section{Summary}

Continual advances have been made in TR technologies, and the use of TR has recently been recognized as an evolving treatment modality by different rehabilitation disciplines. TR could be used as an adjunct or supplement to conventional rehabilitation when these infrastructures are difficult for patients to access due to their geographic location, and reduces the patients' travel times and costs. The feasibility of TR in various aspects such as acceptability, practicality, and effectiveness may need further investigation.

\section{Cross-References}

\author{
- Gerontechnology \\ $\checkmark$ mHealth \\ - Prehabilitation in Older Adults with Cancer \\ - Rehabilitation in Older Adults with Cancer \\ - Technology and Telemedicine \\ $\checkmark$ Telehealth \\ - Telemedicine \\ $\checkmark$ Telenursing
}

\section{References}

Agostini M, Moja L, Banzi R et al (2015) Telerehabilitation and recovery of motor function: a systematic review and meta-analysis. J Telemed Telecare 21(4):202-213. https://doi.org/10.1177/1357633X15572201

Amatya B, Galea MP, Kesselring J, Khan F (2015) Effectiveness of telerehabilitation interventions in persons with multiple sclerosis: a systematic review. Mult Scler Relat Disord 4(4):358-369. https://doi.org/ 10.1016/j.msard.2015.06.011
Bergquist T, Gehl C, Lepore S, Holzworth N, Beaulieu W (2008) Internet-based cognitive rehabilitation in individuals with acquired brain injury: a pilot feasibility study. Brain Inj 22(11):891-897. https://doi. org/10.1080/02699050802405487

Block VAJ, Pitsch E, Tahir P et al (2016) Remote physical activity monitoring in neurological disease: a systematic review. PLoS One 11(4). https://doi.org/10.1371/ journal.pone. 0154335

Boehm N, Muehlberg H, Stube JE (2015) Managing poststroke fatigue using telehealth: a case report. Am J Occup Ther 69(6). https://doi.org/10.5014/ajot.201 5.016170

Botsis T, Demiris G, Pedersen S, Hartvigsen G (2008) Home telecare technologies for the elderly. J Telemed Telecare 14:333-337. https://doi.org/10.1258/jtt.200 8.007002

Breeden LE (2016) Occupational therapy home safety intervention via telehealth. Int $\mathrm{J}$ Telerehabil 8(1):29-40. https://doi.org/10.5195/ijt.2016.6183

Brennan DM, Tindall L, Theodoros D et al (2011) A blueprint for telerehabilitation guidelines-October 2010. Telemed J E Health 17(8):662-665. https://doi. org/10.1089/tmj.2011.0036

Cason J (2009) A pilot telerehabilitation program: delivering early intervention services to rural families. Int J Telerehabil 1(1):29-38. https://doi.org/10.5195/ijt.2 009.6007

Cason J (2012) Telehealth opportunities in occupational therapy through the Affordable Care Act. Am J Occup Ther 66:131-136. https://doi.org/10.5014/ajot.2012.66 2001

Cason J (2014) Telehealth: a rapidly developing service delivery model for occupational therapy. Int J Telerehabil 6(1):29-35. https://doi.org/10.5195/ijt.2 014.6148

Criss MJ (2013) School-based telerehabilitation in occupational therapy: using telerehabilitation technologies to promote improvements in student performance. Int J Telerehabil 5(1):39-46. https://doi.org/10.5195/ ijt.2013.6115

Cross TP, Walsh WA, Cross EM (2018) National telenursing center: program evaluation final report. University of Illinois at Urbana-Champaign, Urbana, IL.

Dorstyn D, Mathias J, Denson L (2013) Applications of telecounselling in spinal cord injury rehabilitation: a systematic review with effect sizes. Clin Rehabil 27(12):1072-1083. https://doi.org/10.1177/02692155 13488001

Eysenbach G, Kairy D, Peterson S et al (2017) Evidence of benefit of telerehabitation after orthopedic surgery: a systematic review. J Med Internet Res 19(4):e142. https://doi.org/10.2196/jmir.6836

Ferre CL, Brandão M, Surana B, Dew AP, Moreau NG, Gordon AM (2017) Caregiver-directed home-based intensive bimanual training in young children with 
unilateral spastic cerebral palsy: a randomized trial. Dev Med Child Neurol 59(5):497-504

Gibbs V, Toth-Cohen S (2011) Family-centered occupational therapy and telerehabilitation for children with autism spectrum disorders. Occup Ther Health Care 25(4):298-314. https://doi.org/10.1111/dmcn.13330

Golomb MR, McDonald BC, Warden SJ, Yonkman J, Saykin AJ, Shirley B, . . Burdea GC (2010) In-home virtual reality videogame telerehabilitation in adolescents with hemiplegic cerebral palsy. Arch Phys Med Rehabil 91(1):1-8.e1. https://doi.org/10.1016/j. apmr.2009.08.153

Hegel MT, Lyons KD, Hull JG, Kaufman P, Urquhart L, Li Z, Ahles TA (2011) Feasibility study of a randomized controlled trial of a telephone-delivered problemsolving: occupational therapy intervention to reduce participation restrictions in rural breast cancer survivors undergoing chemotherapy. Psycho-Oncology 20(10):1092-1101. https://doi.org/10.1002/pon.1830

Hermann VH, Herzog M, Jordan R, Hofherr M, Levine P, Page SJ (2010) Telerehabilitation and electrical stimulation: an occupation-based, client-centered stroke intervention. Am J Occup Ther 64(1):73-81. https:// doi.org/10.5014/ajot.64.1.73

Huang K, Liu W, He D et al (2015) Telehealth interventions versus center-based cardiac rehabilitation of coronary artery disease: a systematic review and metaanalysis. Eur J Prev Cardiol 22(8):959-971. https:// doi.org/10.1177/2047487314561168

Hung Kn G, Fong KN (2019) Effects of telerehabilitation in occupational therapy practice: a systematic review. Hong Kong J Occup Ther 32(1):3-21. https://doi.org/ $10.1177 / 1569186119849119$

Hung K, Zhang Y-T, Tai B (2004) Wearable medical devices for tele-home healthcare. Conf Proc IEEE Eng Med Biol Soc 2004:5384-5347. https://doi.org/ 10.1109/IEMBS.2004.1404503

Johansson T, Wild C (2011) Telerehabilitation in stroke care - a systematic review. J Telemed Telecare 17:1-6. https://doi.org/10.1258/jtt.2010.100105

Kairy D, Lehoux P, Vincent C, Visintin M (2009) A systematic review of clinical outcomes, clinical process, healthcare utilization and costs associated with telerehabilitation. Disabil Rehabil 31:427-447. https:// doi.org/10.1080/09638280802062553

Khan F, Amatya B, Kesselring J, Galea M (2015) Telerehabilitation for persons with multiple sclerosis. Cochrane Database Syst Rev 4:CD010508. https://doi. org/10.1002/14651858.CD010508.pub2

Kornowski R, Zeeli D, Averbuch M et al (1995) Intensive home-care surveillance prevents hospitalization and improves morbidity rates among elderly patients with severe congestive heart failure. Am Heart J 129:762-766. https://doi.org/10.1016/0002-8703(9 5)90327-5

Lawson S, Tang Z, Feng J (2017) Supporting stroke motor recovery through a mobile application: a pilot study. Am J Occup Ther 71(3):1-5. https://doi.org/10.5014/ ajot.2017.025023
Linder SM, Rosenfeldt AB, Bay RC, Sahu K, Wolf SL, Alberts JL (2015) Improving quality of life and depression after stroke through telerehabilitation. Am J Occup Ther 69(2):1-11. https://doi.org/10.5014/ ajot.2015.014498

Mani S, Sharma S, Omar B, Paungmali A, Joseph L (2016) Validity and reliability of internet-based physiotherapy assessment for musculoskeletal disorders: a systematic review. J Telemed Telecare. https://doi.org/10.1177/ 1357633X16642369

McCue M, Fairman A, Pramuka M (2010) Enhancing quality of life through telerehabilitation. Phys Med Rehabil Clin N AM 21(1):195-205. https://doi.org/ 10.1016/j.pmr.2009.07.005

McKay FH, Cheng C, Wright A, Shill J, Stephens H, Uccellini M (2018) Evaluating mobile phone applications for health behaviour change: a systematic review. J Telemed Telecare 24(1):22-30. https://doi.org/ 10.1177/1357633X16673538

Ng EMW, Polatajko HJ, Marziali E, Hunt A, Dawson DR (2013) Telerehabilitation for addressing executive dysfunction after traumatic brain injury. Brain Inj 27(5):548-564. https://doi.org/10.3109/02699052.201 3.766927

Nix J, Comans T (2017) Home quick: occupational therapy home visits using mHealth, to facilitate discharge from acute admission back to the community. Int J Telerehabil 9(1):47-54. https://doi.org/10.5195/ ijt.2 017.6218

Peretti A, Amenta F, Tayebati SK, Nittari G, Mahdi SS (2017) Telerehabilitation: review of the state-of-the-art and areas of application. JMIR Rehabil Assist Technol 4(2):e7. https://doi.org/10.2196/rehab.7511

Ponce BA, Jennings JK, Clay TB, May MB, Huisingh C, Sheppard ED (2014) Telementoring: use of augmented reality in orthopaedic education: AAOS exhibit selection. J Bone Joint Surg Am 96(10):e84. https://doi.org/ 10.2106/JBJS.M.00928

Reifenberg G, Gabrosek G, Tanner K, Harpster K, Proffitt R, Persch A (2017) Feasibility of pediatric game-based neurorehabilitation using telehealth technologies: a case report. Am J Occup Ther 71(3):1-8. https://doi.org/10.5014/ajot.2017.024976

Santos MTND, Moura SCDO, Gomes LMX, Lima AH et al (2014) Telehealth application on the rehabilitation of children and adolescents. Rev Paul Pediatr 32(1):136-143. https://doi.org/10.1590/s0103-058220 14000100020

Sharifi M, Salarieh H, Behzadipour S, Tavakoli M (2018) Patient-robot-therapist collaboration using resistive impedance controlled tele-robotic systems subjected to time delays. J Mech Robot 10(6):061003. https:// doi.org/10.1115/1.4040961

Souza-Junior VD, Mendes IAC, Mazzo A, Godoy S (2016) Application of telenursing in nursing practice: an integrative literature review. Appl Nurs Res 29:254-260. https://doi.org/10.1016/j.apnr.2015.05.005

Theodoros DG (2008) Telerehabilitation for service delivery in speech-language pathology. J Telemed 
Telecare 14(5):221-224. https://doi.org/10.1258/jtt.20 07.007044

World Confederation for Physiotherapy (WCPT), International Network of Physiotherapy Regulatory Authorities (INPTRA) (2019) Report of the WCPT/ INPTRA digital physical therapy practice task force. Accessed 6 Apr 2020 from http://www.inptra.org/portals/0/pdfs/ ReportOfTheWCPTINPTRA_DigitalPhysicalTherapy Practice_TaskForce.pdf
World Federation of Occupational Therapists (WFOT) (2014) World Federation of Occupational Therapists' position statement on telehealth. Int $\mathrm{J}$ Telerehabil 6(1):37-39. https://doi.org/10.5195/IJT.2014.6153

World Health Organization, Group Consultation on Health Telematics (1998) A health telematics policy in support of WHO's Health-for-All Strategy for Global Health Development (WHO/DGO/98.1):10. World Health Organization, Geneva 